\title{
ZADRUGARSTVO I DRUŠTVENO ODGOVORNO POSLOVANJE
}

\author{
Stjepan Car, Robert Pašičko i Zoran Kordić
}

\author{
Zelena energetska zadruga \\ Ivana Bunića Vučića 21, 10000 Zagreb \\ e-mail: stjepan.car49@gmail.com
}

\begin{abstract}
Sažetak
Zadruga kao neovisno udruženje osoba koje udružuju rad za razliku od dioničkog društva u kojem se spaja kapital, organizacijski je oblik udruživanja radi zadovoljavanja zajedničkih ekonomskih, socijalnih ili kulturnih potreba na demokratičan način. Energetske zadruge, koje su naročito proširene u nekim europskim zemljama, predstavljaju oblik zadruga koje su izravno usmjerene na rješavanje energetskih i ekoloških problema, koje stabiliziraju lokalno gospodarstvo, odgovaraju na potrebe ljudi u zajednici, stvaraju pravednije sustave raspodjele dobiti i doprinose povećanju općeg dobra. Društveno poduzetništvo kao noviji način poslovanja predstavlja područje preklapanja poduzetničkih praksi iz poslovnog svijeta i vrijednosti usko povezanih s društvenom odgovornošću. Druśtveno odgovorno poslovanje i ovdje podrazumijeva apsolutno poštivanje svih zakona i propisa uz vođenje brige o resursima i okolišu ali i o zadružnim načelima koja podrazumijevaju: dobrovoljno i otvoreno članstvo, demokratsko upravljanje i nadzor, ekonomsko sudjelovanje članova, autonomiju i nezavisnost zadruge, omogućavanje obrazovanja $i$ informiranja članova, suradnju medu zadrugama i brigu o zajednici u kojoj djeluju.

Na primjeru djelovanja i rada Zelene energetske zadruge, Zagreb, bit će opisan inovativni poslovni model u sektoru energetike koji doprinosi energetskoj tranziciji i razvoju društvenog poduzetništva u Hrvatskoj.
\end{abstract}

Ključne riječi: društvena odgovornost, održivi razvoj, zadruga, društveno poduzetništvo, skupno financiranje, lokalna zajednica

\section{UVOD}

Postoji više definicija društvene odgovornosti, a možda je najopćenitija ona prema definiciji International Business Leaders Forum-a (IBLF). Društvena odgovornost podrazumijeva promicanje odgovorne prakse u gospodarstvu koja gospodarstvu i društvu koristi i olakšava ostvarenje društvenog, gospodarskog i ekološki održivog razvoja s maksimalno pozitivnim utjecajem gospodarstva na društvo, uz istovremeno svođenje negativnih učinaka na minimum (prema Ćorić, 2008).

Komisija UN-a definirala je 1987. održivi razvoj kao onaj koji zadovoljava potrebe sadašnjosti bez ugrožavanja mogućnosti budućim generacijama da zadovolje svoje potrebe. Temelj su održivom razvoju: demokracija, slobodno tržište i odgovorno upravljanje prirodnim resursima. Održivi razvoj ima gospodarsku, društvenu te dimenziju okoliša, a postao je nezaobilazan pojam današnjice $s$ obzirom na intenzivno korištenje neob- 
novljivih prirodnih resursa i nepopravljivog utjecaja na okoliš kao i širenja razarajućih društvenih odnosa. Dok je pojam odgovornost etički pojam, društvena je odgovornost pojam koji se odnosi na cjelokupno djelovanje pojedinca ili neke organizacije na sve odnose koji se uspostavljaju pri njihovom djelovanju.

Europska komisija u Smjernicama za politiku društvene odgovornosti poduzeća (EC White paper on Corporate Social Responsibility, 2003, prema Ćorić, 2008) daje preporuke da dio ostvarene dodane vrijednosti u vidu dobiti ostavlja vlasnicima poduzeća, definira društveno odgovorno poslovanje (DOP) kao koncept upravljanja poduzećem prema kojem poduzeće, provodeći svoje poslovne aktivnosti i odnose s dionicima, dobrovoljno brine o društvenim problemima i zaštiti okoliša.

Kohezijska politika Europske komisije ima za cilj smanjiti razlike između regija i osigurati razvoj cijeloj Europi, a glavni su alat za provođenje takve politike strukturni fondovi (Car i sur., 2019). Između ostalog, oni potiču nisko ugljično gospodarstvo i primjenu kružne ekonomije, kojima se manje troše prirodni resursi i štiti okolišs, kao ključni elementi društveno odgovornog poslovanja.

Važna su područja razvoja nisko ugljičnog gospodarstva svakako:

- provođenje energetske učinkovitosti,

- primjena obnovljivih izvora energije i

- primjena tehnoloških i društvenih inovacija,

a sve uz primjenu strategije pametne specijalizacije odnosno fokusiranja na područja s najviše resursa i tržišnih prilika (Kirinčić, 2018).

\section{ZADRUGA KAO PODUZETNIČKA ORGANIZACIJA}

U EU danas ima više od 250.000 zadruga s oko 160 milijuna zadrugara i 5,4 milijuna zaposlenih što čini oko 2,5\% svih zaposlenih u EU (Europska komisija, 2010, prema Babić i Račić, 2011). U Hrvatskoj slika je sasvim drugačija: danas ima svega oko 1.250 zadruga s oko 22.000 zadrugara i 2.730 zaposlenih (Stanojević, 2015:52) što predstavlja oko 0,2\% svih zaposlenih (Babić i Račić, 2011).Iako je pojam zadruga korišsten i u komunističkom sustavu u kojem su zadruge radile na sasvim drugim vlasničkim i netržišnim principima, danas je zadruga oblik poduzetničke organizacije koji ima međunarodno dogovorenu i priznatu definiciju te vrijednosti i načela. Međunarodne smjernice zadružnih načela su:

a) dobrovoljno i otvoreno članstvo za sve koji su voljni prihvatiti odgovornosti koje nosi članstvo,

b) demokratsko upravljanje članova koji aktivno sudjeluju u upravljanju i odlučivanju,

c) ekonomsko sudjelovanje članova tako da ravnopravno doprinose i demokratski odlučuju o kapitalu zadruge,

d) autonomnost i nezavisnost i u slučaju suradnje s drugim organizacijama ili državnim tijelima ili vanjskim izvorima kapitala, 
e) obrazovanje, obuka članova ili predstavnika i informiranje šire javnosti o prirodi i koristima zadrugarstva,

f) suradnja među zadrugama kao učinkovito sredstvo za širenje zadružnog pokreta na lokalnoj, nacionalnoj i međunarodnoj suradnji i

g) skrb za zajednicu, jer one rade na održivom razvoju zajednica u kojima djeluju putem pravila koja su odobrili njezini članovi (Rodgers, 2015).

Početak zadrugarstva u Hrvatskoj može se smatrati 1862. osnivanjem prve zadruge u Pitomači pod nazivom Pitomačka zanatnička zadružnica (Lauš, 1981; Hrvatski poljoprivredni zadružni savez, 2019). U Republici Hrvatskoj prvi Zakon o zadrugama donesen je 1995. koji je 2011. zamijenjen novim Zakonom o zadrugama. Godine 2002. osnovan je Hrvatski savez zadruga koji je 2014. promijenio ime u Hrvatski centar za zadružno poduzetništvo, a koji je Vladinom uredbom od 01.01.2019. pripojen Ministarstvu gospodarstva, poduzetništva i obrta.

Prema Zakonu o zadrugama (NN 34/11, 125/13, 76/14, 114/18, 98/19), zadrugu može osnovati najmanje 7 dionika / članova koji udružuju svoj rad uz jednako učešće u kapitalu, a u svrhu bavljenja registriranom djelatnošću radi stjecanja dobiti kojom sa $70 \%$ raspolažu svi dionici razmjerno sudjelovanjem u radu. Od preostale dobiti prema Zakonu mora se $20 \%$ zadržati za razvoj zadruge, a $5 \%$ raspoređuje se za pričuvu. Dionici snose rizik poslovanja samo do visine svojih uloga. Temeljni su akt zadruge pravila zadruge. Organi upravljanja zadrugom su: skupština zadrugara $i$ upravitelj zadruge, a ovisno o broju zadrugara i nadzorni odbor. Zadruga mora imati i Odbor za članstvo koji razmatra prijave za članstvo i pritužbe postojećih članova, a može predložiti i brisanje članova uz povlačenje uloga i pripadajuće dobiti.

\section{ODNOS ZADRUGE PREMA PRIRODNIM RESURSIMA I LOKALNOJ ZAJEDNICI}

Svaka lokalna zajednica ima neke potencijale koje treba prepoznati i koristiti ih za brži razvoj. To su prije svega:

- prirodni resursi: voda, sunce, vjetar, biomasa, geotermalni izvori...

- ljudski potencijali: građani školovani za buduće potrebe lokalne zajednice i

- kapital gradana pojedinačno malog iznosa, ali velikog kod grupnog financiranja (Kirinčić, 2018).

Radi što učinkovitijeg korištenja tih potencijala, od lokalne se zajednice očekuje da:

- dodatno potiče obrazovanje za stvaranje tehnoloških i društvenih inovacija kao i da

- inicira i potiče društveno poduzetništvo na korištenju prirodnih resursa lokalne zajednice putem organiziranja i osnivanja: specijaliziranih zadruga, civilnih udruga, javnih tvrtki...(Kirinčić, 2018).

Tranzicija u energetskom sektoru koju provodi komisija EU-a kroz svoje direktive i uredbe prilika je za razvoj lokalnih zajednica i društvenog poduzetništva. Građanska energija koja podrazumijeva energetska postrojenja u vlasništvu ili suvlasništvu građana i / ili lokalne zajednice omogućuje razvoj novih zelenih radnih mjesta na uzgoju i 
zbrinjavanju biomase, recikliranju otpada, izgradnji opreme za energetska postrojenja, inženjering poslova i slično (Kirinčić, 2018). Takve su društvene inovacije vrlo korisne za brži gospodarski i društveni razvoj lokalnih zajednica (Car, 2019).

Kao i kod drugih oblika organiziranja i kod zadruga poželjna je primjena međunarodnih normi u području upravljanja, a prije svega normi:

- ISO 9001 za upravljanje kvalitetom proizvoda / usluga,

- ISO 14001 za upravljanje okolišem i proizvoda prema okolišu,

- OHSAS 18001 za upravljanje sigurnošću i zaštitom zdravlja,

- ISO 50001 za energetsku učinkovitost,

- ISO 27001 za upravljanje informacijskom sigurnošću, itd.

Stoga poslovanje zadruga predstavlja dobar primjer društveno odgovornog poslovanja koje pomiruje ekonomski i društveni interes, a koji su najčešće zapisani i u njihovoj misiji i viziji.

\section{PRIMJER POSLOVANJA ZELENE ENERGETSKE ZADRUGE}

Misija Zelene energetske zadruge (ZEZ) pomaganje je gradanima i javnom sektoru u razvoju, investiranju i korištenju obnovljivih izvora energije, s vizijom udruživanja znanja, vjestina $i$ rada za poticanje lokalne proizvodnje energije iz obnovljivih izvora i njezino učinkovito korištenje, pridonoseći tako održivom razvoju društva.

Zadruga ZEZ osnovana je u Zagrebu 2013. i trenutno ima ukupno 20 članova s akademskim obrazovanjem i dugogodišnjim iskustvom od kojih petorica imaju zvanje doktora znanosti. Šest je članova u trajnom radnom odnosu, a ostali članovi rade povremeno kao vanjski suradnici sa specifičnim znanjima koja stječu i razvijaju na mjestima njihovog trajnog zaposlenja ili su pak umirovljenici. Poslovne aktivnosti ZEZ-a vezane su za usluge savjetovanja korištenja obnovljivih izvora i održivog razvoja primjenom novih poslovnih modela i novih tehnologija kao i grupno financiranje ili sufinanciranje izgradnje postrojenja koja koriste obnovljive izvore ili povećavaju energetsku učinkovitost. Tržišta Zadruge su: Hrvatska, EU putem projekata financiranih iz EU fondova i članstva u europskom udruženju energetskih zadruga, kao i zemlje zapadnog Balkana (Car i sur., 2019).

Za pojedine projekte fotonaponskih elektrana (FNE) na objektima lokalne uprave, ZEZ izrađuje studije izvodljivosti, predlaže izbor objekata i veličinu elektrane ovisno o vlastitoj potrošnji i mogućim uštedama eventualnim promjenama rasvjete, hlađenja ili grijanja te gradi elektranu sredstvima prikupljenim od građana u vidu mikro zajmova. Pri odabiru lokacije ne vrednuje se samo profitabilnost same elektrane nego se može vrednovati i društvena prihvatljivost projekta s obzirom na:

- doprinos u smanjenju emisije stakleničkih plinova,

- broj trajno novozaposlenih,

- uključenost građana u vlasništvo kao i

- drugi elementi važni za lokalnu zajednicu. 


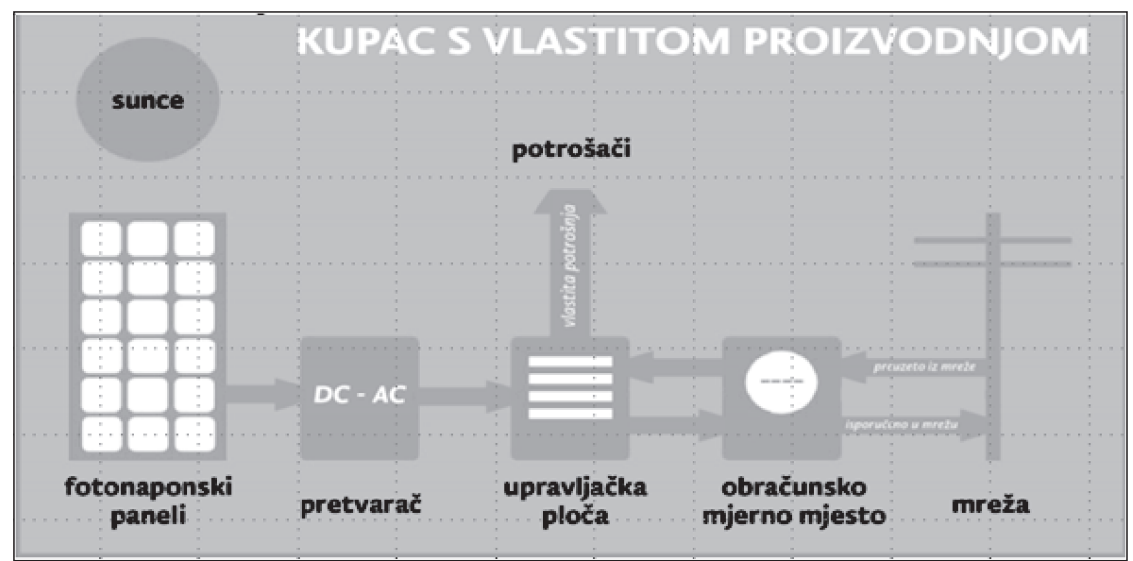

Slika 1. Fotonaponska elektrana po modelu ,kupac s vlastitom proizvodnjom “(Kordić, 2019; NN 100/15, 123/16, 131/17, 111/18)

Vlasnik objekta daje mjesto za izgradnju FNE u najam ZEZ-u i obvezuje se da će kupovati električnu energiju od ZEZ-a kao investitora i vlasnika elektrane, ali i kao organizatora poslovnog modela. Nakon perioda otplate investicije, ZEZ besplatno ustupa FNE u trajno vlasništvo najmodavca prostora na kojem je ona izgrađena. Ovisno o lokaciji, vrsti potrošača i mogućim uštedama period otplate investicije iznosi 6-10 godina, a investitori godišnje dobivaju dio glavnice i kamatu na uložena sredstva u visini $2-4 \%$ sve do cjelokupne otplate. To je način da građani aktivno sudjeluju u energetskoj tranziciji u svojoj lokalnoj zajednici. Po jednakom ili sličnom modelu mogu se organizirati i drugi razvojni projekti koji podižu standard življenja u lokanoj zajednici.

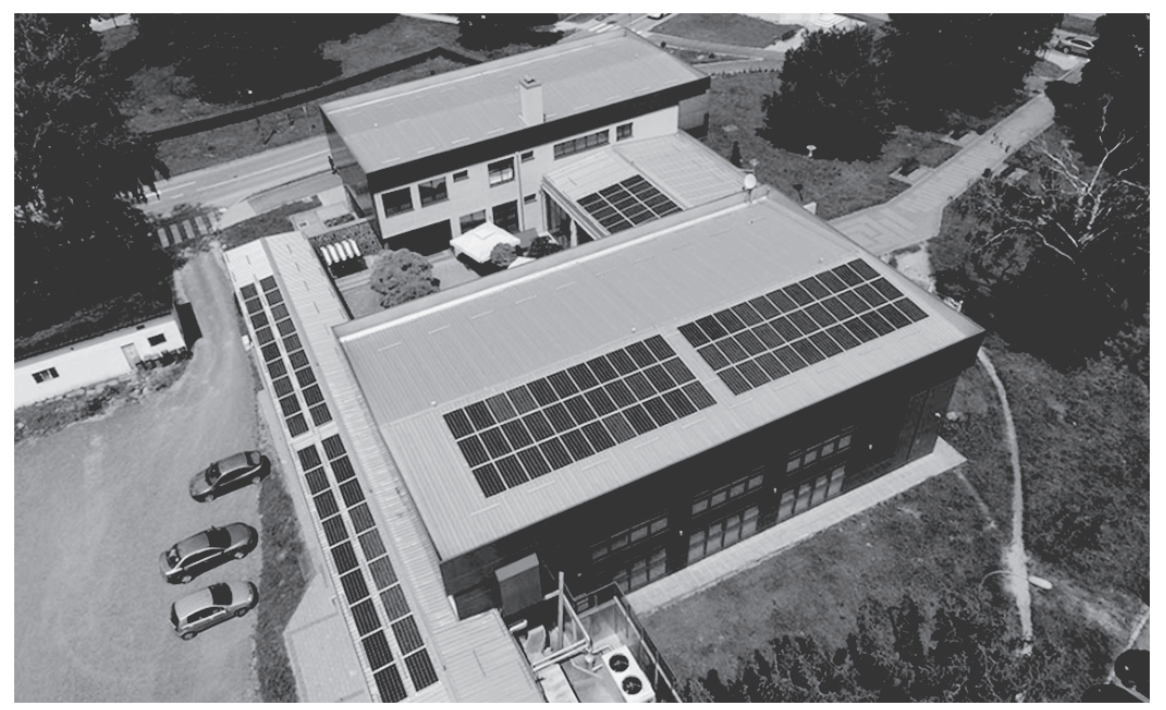

Slika 2. Fotonaponska elektrana u Križevcima izgradena poslovnim modelom grupnog financiranja gradana (Kordić, 2019) 
Dakle, izgradnja FNE po modelu grupnog financiranja (Car i sur., 2019), ne zahtijeva od budućeg vlasnika elektrane početna ulaganja, nego uz jednaki trošak za električnu energiju, a nakon isplate mikro zajmova, donose vlasniku trajne uštede u troškovima za energiju, pridonose smanjenju emisije stakleničkih plinova i novom zapošljavanju. Omogućuju, također, da mali ulagači ostvare zaradu umjesto da to učine banke te se time potiče razvoj lokalne zajednice.

$\mathrm{Na}$ Slici 1. prikazana je shema FNE po modelu kupca električne energije $s$ vlastitom proizvodnjom a na Slici 2 izvedba FNE u Križevcima na javnom objektu Tehnološkog parka.

\section{ZAKLJUČAK}

Društveno odgovorno poslovanje može biti ugrađeno u same temelje poslovanja zadruga kao novijeg oblika poduzetničkog organiziranja u kojoj članovi udružuju rad uz jednake udjele u kapitalu. Zadrugarstvo je moderan način organiziranja poduzetništva koji podrazumijeva dobrovoljno i otvoreno članstvo, demokratsko i nezavisno upravljanje, ekonomsko sudjelovanje, obrazovanje i informiranje članova, kao i brigu o zajednici u kojoj djeluje. Energetska je tranzicija dobra prilika za razvoj lokalnih zajednica putem energetskih zadruga koje mogu potaknuti i uključiti lokalno stanovništvo na izgradnju i korištenje obnovljivih izvora, ne samo aktivnim uključenjem u članstvo zadruga nego grupnim financiranjem u tzv. zelene projekte radi ostvarivanja ne samo vlastite, nego i društvene koristi. 


\section{LITERATURA:}

Babić, Z. i Račić, D. (2011). Zadrugarstvo u Hrvatskoj: trendovi, pokazatelji i perspektiva u europskom kontekstu. Sociologija i prostor, 49(3): 287-311.

Car, S. (2019). Inovacije kao pokretač gospodarskog napretka i društvenih promjena. Suvremena trgovina, 44(3): 23-27.

Car, S., Pašičko, R. i Kordić, Z. (2019). Moguća uloga obnovljivih izvora energije u razvoju lokalnih zajednica, Polytecnic and Design, 7(1): 60-65.

Ćorić, G. (2008). Što je društvena odgovornost? Pomakonline - Magazin za društveni razvitak, 15. travnja 2008. URL: http://www.pomakonline.com/content/ view/100/60/ (08.06.2020.)

Hrvatski poljoprivredni zadružni savez (2019). Povijest zadrugarstva u Hrvatskoj. URL: http://www.hzs.hr/o_zadruzi.htm (08.06.2020.)

Kirinčić, V. (2018). Moguća uloga obnovljivih izvora u razvoju lokalnih zajednica. Projekt Empowering Horizon 2020 - Platforma za učenje. Kako odabrati aktivnosti (mjere) za vaš SECAP.Pula, 14. ožujka 2018. URL: https://empowering2020.eu/ wp-content/uploads/Crowdfunding.pdf (08.06.2020.)

Kordić, Z. (2019). Mogućnosti realizacije projekata sunčanih elektrana po modelu grupnog ulaganja. Konferencija o mogućnostima korištenja sunca za proizvodnju električne energije. Pučko otvoreno učilište, Velika Gorica, 29. studenog 2019.

Lauš, M. (1981). Prva obrtna štedno-kreditna zadruga u Pitomači. Podravski zbornik, 7: 110-117.

Rodgers, D. (ur.) (2015). Smjernice o zadružnim načelima. Bruxelles: Međunarodni savez zadruga. URL: https://www.ica.coop/sites/default/files/publication-files/2017-02-15-hrguidance-notefinal-581762885.pdf (08.06.2020.)

Stanojević, I. (2015). Analiza zadružnog sustava u 2014. godini. Agroeconomia Croatica, 5(1): 51-57.

Zakon o obnovljivim izvorima energije i visokoučinkovitoj kogeneraciji. Narodne novine, 100/15, 123/16, 131/17, 111/18.

Zakon o zadrugama. Narodne novine, 34/11, 125/13, 76/14, 114/18, 98/19. 


\title{
COOPERATIVES AND COOPERATIVE SOCIAL RESPONSIBILITY
}

\author{
Stjepan Car, Robert Pašičko and Zoran Kordić
}

\begin{abstract}
A cooperative is an independent association of people who combine their work as opposed to joint stock companies in which they combine their capital. It is a type of organization established with the aim to meet common economic, social or cultural needs in a democratic way. Energy cooperatives, which are particularly widespread in some European countries, are a type of cooperatives which primarily aim to resolve energy and environmental problems, stabilize the local economy, meet the needs of people in the community, create fairer distribution systems and contribute to the common good. Social entrepreneurship as a new way of doing business combines entrepreneurial practices from the business world and values related to social responsibility. In that sense, a socially responsible business implies absolute compliance with all laws and regulations but also takes care of the resources and the environment as well as follows the cooperative principles, such as: voluntary and open membership, democratic governance and supervision, economic participation of members, autonomy and independence of cooperatives, providing education and information to members, cooperation between cooperatives and care for the communities in which they operate.

In this paper, we analyse the activities of Green Energy Cooperative in Zagreb as an example of an innovative business model in the energy sector that contributes both to the energy transition and the development of social entrepreneurship in Croatia.
\end{abstract}

Keywords: social responsibility, sustainable development, cooperatives, social entrepreneurship, co-financing, local community

\section{GENOSSENSCHAFTSGEDANKE UND SOZIAL VERANTWORTLICHE GESCHÄFTSTÄTIGKEIT}

\author{
Stjepan Car, Robert Pašičko und Zoran Kordić
}

\section{Zusammenfassung}

Eine Genossenschaft ist eine unabhängige Vereinigung von Personen, die ihre Arbeit vereinigen, anders als bei einer Aktiengesellschaft, wo man Kapital vereinigt, also eine Organisationsform mit dem Zweck, gemeinsamen ökonomischen, sozialen oder kulturellen Bedürfnissen auf eine demokratische Art nachzugehen. Energiegenossenschaften, die besonders in einigen europäischen Ländern verbreitet sind, stellen eine Form der Genossenschaften dar, die unmittelbar auf die Lösung von energetischen und ökologischen Problemen gerichtet sind, die die lokale Wirtschaft stabilisieren, den Bedürfnissen der Menschen in einer Gemeinschaft entsprechen, gerechtere Systeme der Profitverteilung schaffen und der Steigerung des Allgemeinwohlstands beitragen. Soziales Unternehmertum als eine neuere Art der Geschäftstätigkeit stellt ein Segment dar, wo sich Unternehmenspraktiken aus der Geschäftswelt mit den Werten der sozialen Verantwortung überlappen. Sozial verantwortliche Geschäftstätigkeit impliziert auch, dass man sich hier absolut an alle Gesetze und Vorschriften hält und sich um Ressourcen und die Umwelt kümmert, sowie auf genossenschaftliche Prinzipien achtet und darunter versteht man: freiwillige und offene Mitgliedschaft, demokratische Verwaltung und Aufsicht, wirtschaftliche Teilnahme der Mitglieder, Autonomie und Unabhängigkeit von Genossenschaften, Ermöglichung von Bildung und Informiertheit von Mitgliedern, Zusammenarbeit unter Genossenschaften und Sorge für die Gemeinschaft, in der sie aktiv sind.

Am Beispiel der Aktivitäten der Grünen Energiegenossenschaft, Zagreb, beschreiben wir das innovative Geschäftsmodel im Energiesektor, das der energetischen Transition und der Entwicklung des sozialen Unternehmertums in Kroatien beiträgt.

Schlüsselwörter: soziale Verantwortung, nachhaltige Entwicklung, Genossenschaften, soziales Unternehmertum, Gruppenfinanzierung, lokale Gemeinschaft 